\title{
Does A Business Curriculum Develop Or Filter Critical Thinking?
}

B. Jay Coleman, University of North Florida, USA

Paul Mason, University of North Florida, USA

Jeffrey W. Steagall, Weber State University, USA

\begin{abstract}
We investigate whether a business curriculum develops critical thinking ability or at least serves as a filter for critical thinking (i.e., students who cannot think critically tend not to progress toward graduation). We measure critical thinking by performance on the Watson-Glaser Critical Thinking Appraisal Short Form which was administered to a sample of 600 students enrolled in a junior-level operations management course. We find that students who have completed more credit hours score significantly higher than those with fewer hours completed. This advantage appears specifically evident in the areas of interpreting information and evaluating arguments.
\end{abstract}

Keywords: Critical Thinking; Business Curriculum; Watson-Glaser

\section{INTRODUCTION}

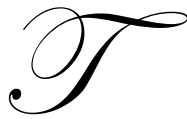

he ability to think critically has always been important for success in business. However, it is arguably becoming an increasingly vital skill in the modern economy. The speed and hyper competitiveness of business in the era of globalization imply, particularly for citizens of developed nations, that it is necessary to be able to observe, analyze, evaluate, and react creatively to changing situations.

Business schools have long argued that they foster critical thinking skills, both through curriculum design and through course delivery. However, such claims are seldom backed by sound empirical design and experimentation. Moreover, even when rigorous methodology is applied, it can remain unclear whether students' critical thinking skills are enhanced by the curriculum. One explanation is that progressing through the business curriculum enhances the critical thinking skills of students, which is the view implicit in most claims. However, it is also possible that the business curriculum merely filters for good critical thinkers. In that scenario, students who begin with poor critical thinking skills self-select into other majors, while only good critical thinkers progress toward graduation. However, the progress of good critical thinkers is based upon their a priori critical thinking skills; the business curriculum does little or nothing to enhance them. This paper seeks to distinguish between these competing explanations.

\section{LITERATURE REVIEW}

A very recent article in this journal, Behar-Horenstein and Lian Niu (2011), reviews the general literature regarding the teaching of critical thinking skills at the post-secondary level. Specifically, they argue that "future research should properly address internal validity threats, e.g. by adopting at least a quasi-experimental design, in order to establish causal relationship between intervention and changes in students' critical thinking skills." This paper is true to this notion through systematic quantitative analysis of students' performance on a standardized test of several critical thinking measures across a diverse sample of students in a college of business. We also follow their recommendation by discussing the generality of our results without concluding that one size fits all.

Rudinow and Barry (1994) define critical thinking as a process that emphasizes a rational basis for what we believe and provides standards and procedures for analyzing, testing and evaluating our beliefs. Williams (2002) provides a concise summary of the practice of successful critical thinking. He begins with the Rudinow and Barry 
presumption that critical thinking is grounded in rationality then proceeds to identify the common barriers to successful critical thinking. These include, among others, the influence of our desires on the solutions we develop; various biases that influence our thinking; and the very difficult time that human beings have in accurately comprehending uncertainty and risk. He then provides a framework with which businesspeople and ordinary citizens can enhance their critical thinking skills. His recommendations include improving problem identification and idea generation, as well as examining proposed solutions for validity. He also focuses on the importance of creativity for problem-solving. The business curriculum, and particularly its quantitatively-oriented courses, is typically designed to teach students the same problem-solving behavior. Thus, we expect that it should lead to improved critical thinking by business students as they progress toward graduation. Other references have alternative approaches to teaching critical thinking skills. Stratton (1999) provides a more rigorous treatment of critical thinking for college students, but does it in a general context, rather than a business framework. Fisher (2001) provides readers with numerous examples designed to help them practice thinking critically as they work through the text.

Giancarlo and Facione (2001) studies how attributes of critical thinking evolved in students attending a liberal arts university. Their data derive from the California Critical Thinking Disposition Inventory (CCTDI), which students took in their freshman year and again four years later. She observed significant differences in the scores for truth-seeking and critical thinking self-confidence, as well as in the overall CCTDI score. MacPherson (1999) offers pedagogy for using peer-graded oral presentations of literature reviews to assess and enhance critical thinking. She concludes that both the grading paradigm and the content of the literature review are influenced by critical thinking strategies and skills.

While the literature on critical thinking in business is relatively small, the discipline of economics has a richer history of examining the link between learning economics and thinking critically. For example, Borg and Stranahan (2006) investigate the link between the economics knowledge gained in introductory economics courses (as measured by the well-known TUCE test) and students' performance on the Watson-Glaser Critical Thinking Appraisal, the same exam that we use in our analysis. Their empirical results are consistent with the observation that students who acquire more economics knowledge during the economics principles course score higher on the critical thinking exam. Borg and Stranahan provide an excellent literature review, including some references linking technology-based learning exercises (e.g., on-line discussion groups) to critical thinking ability. The reader is referred there for additional information.

Other disciplines are also investigating their influence on students' ability to think critically. Among these, Miller (1992) employs pre- and post-testing of nursing students and finds a statistically significant positive incremental effect on critical thinking scores. Interestingly, they find that the nursing GPA was statistically significantly related to the post-test score, but that general education GPA was not. Her call for curriculum and teaching strategy innovations to enhance critical thinking skills is addressed, for example, by Niedringhaus (2001), who offers a holistic approach that assesses critical thinking skills through writing assignments for nursing students.

\section{Watson-Glaser Critical Thinking Appraisal}

The Watson-Glaser Critical Thinking Appraisal (or WGCTA), the initial version of which was developed in 1952 (Watson and Glaser, 1952) and the precursors of which were developed in 1925 and 1937 by Watson and Glaser, respectively (Watson and Glaser, 2006), is one of the most widely employed objective (i.e., multiple-choice) instruments for measuring critical thinking (Carrithers and Bean, 2008). Indeed, a Google Scholar search in May 2008 revealed over 500 works in which the instrument has been cited and/or used since 1989. The WGCTA comes in two versions: a standard version containing 80 multiple-choice items that is designed to be completed in 60 minutes (Pantesting.com, 2008), and a short form (first published in 1994) containing 40 multiple-choice items that is designed to be completed within 40 minutes, with 10 of these minutes for reading instructions and example problems (Watson and Glaser, 2006). Research on both instruments demonstrates that the short form yields results that are very similar to those on the standard form (Watson and Glaser, 2006). Because of its shorter completion time and lower cost, we administered the short form.

Each version of the instrument is divided into sub-sections measuring five different aspects of critical thinking ability: making accurate inferences (referred to on the instrument as Test 1), recognizing assumptions (Test 
2), making proper deductions (Test 3), interpreting information (Test 4), and evaluating arguments (Test 5) (Harcourt Assessment, 2008). The instrument is designed to measure critical thinking irrespective of content knowledge. It does not require mathematical computation and requires only a ninth-grade education (more than $98 \%$ of the words employed are at or below a ninth-grade reading level) (Watson and Glaser, 2006).

\section{METHODOLOGY}

During the spring, summer, and fall terms of calendar year 2007, the WGCTA short form was administered to 600 students enrolled in 19 sections of a required undergraduate core course in operations management at an urban comprehensive university with a total enrollment of approximately 17,000, and a business school undergraduate enrollment of approximately 3,000. These course sections included nine spring term sections, two summer term sections, and eight fall term sections. This course was selected for administration in part because of the cross section of students enrolled in it. As a required course for all business majors, it offered an opportunity to capture a near census of students with a comprehensive set of demographics. Also, because it is a junior-level course with no business prerequisites, some students take it early in their junior year - meaning for many it is one of the first business courses taken. However, for most business students it is not itself a prerequisite for later required courses, so many students delay taking the course until late in their program of study. The high level of quantitative applications and the perceived and actual rigor associated with the course material likely contributed to many students' decisions to delay taking the course. Thus, the course presented an opportunity to capture a relatively broad cross-section of students in terms of majors, demographics, and credit hours taken.

In all instances, the associate dean in charge of assessment and accreditation administered the exam, reducing any variation in outcomes that might be associated with differences in directions or presentation style. A 75-minute class meeting was set aside to administer the exam and students were given approximately 40 minutes to complete the instrument (research on the WGCTA short form indicates that $90 \%$ of respondents complete the test within 30 minutes (Watson and Glaser, 2006)). All students attending during the selected class meeting were administered the paper-and-pencil version of the instrument. The associate dean preceded the administration with a presentation regarding the tests' role and importance in the college's accreditation processes, and as a quid-pro-quo for each student, promised an individualized report showing his/her scores as well as his/her percentile ranking visà-vis 11 different comparison groups from industry (including senior executives). Stated otherwise, taking the appraisal was presented as an opportunity for self-assessment for the student, and an opportunity to see how they currently compared to those already working in industry. Although students were occasionally given credit by the course instructor for simply taking the appraisal, in no case were students given any sort of course credit based on their actual performance on the appraisal. The lack of course credit approach likely reduced any motivation for cheating from fellow classmates or leakage of appraisal content from one course section to the next, although it is possible that some students did not take the appraisal seriously, with their scores suffering accordingly.

On the appraisal, students were asked to provide their names and student identification numbers. These identification numbers were then used to match student results to demographic information on major, gender, and ethnicity, total credit hours completed at the institution at which the analysis was conducted, and total credit hours transferred into the institution from other schools.

We conducted six separate analyses: one using the overall appraisal score as the dependent variable, operationalized as the number of items (out of 40) answered correctly, and the other five using the percentage of items answered correctly on each of the five tests (or sub-scores). The number of items within each test differed: there were seven items each within tests 1 and 4, eight within test 2, and nine each within tests 3 and 5 . We are aware that Watson and Glaser indicate that it is the collective score that is a reliable critical thinking measure, and that the five sub-scores are not necessarily reliable as measures of specific critical thinking aspects (Watson and Glaser, 2006). However, we thought it of interest to investigate their relationship to our regressors nevertheless, as have previous researchers (e.g., Zascavage, et al., 2007).

The independent variable of interest for investigating our research question was the total number of credit hours completed, including credit hours completed at the target institution plus credit hours transferred from other institutions (because of the very large proportion of students in the study with some number of transfer hours, 
narrowing the analysis to just non-transfers was not feasible.) Control factors included binary variables representing gender (with female as the omitted category), ethnicity (black, Hispanic, or Asian, with white as the omitted category), declared major (accounting, economics, finance, financial services, international business, marketing, and transportation/logistics, with the largest major of management as the omitted category), term administered (summer or fall, with spring as the omitted category), and instructor of the section in which the instrument was administered (there were four instructors, requiring three binary variables). Due to historical and anecdotal observation by the authors, we also hypothesized that transfer students - or those with larger proportions of transferred hours - may be less academically prepared than "native" students (or those with fewer transferred hours). We thus constructed an additional control variable representing the percentage of total credit hours that were completed at another institution. (Almost $89 \%$ of the students in our sample had at least some transfer credit hours, mostly from community colleges.)

We also omitted 16 of the 600 observations in which students were reported as having less than 60 credit hours completed. Sixty hours represented half of the 120 credit hours needed for graduation, the hours needed to rise to junior-level status, the number of lower-division (or non-business) credit hours required of all students, and the number of hours needed by community college students to qualify for automatic transfer into the institution at which the study was conducted. This approach tended to assure that each student included in the analysis had a baseline (and largely non-business) level of college coursework, and left us with 584 observations for analysis.

Summary descriptive statistics for all variables appear in Table 1. Our sample contained almost 53\% males, and approximately $29 \%$ were minorities. The average percentage of total credit hours that were completed at other institutions was $52.4 \%$. The 584 students included in the study averaged 27.67 out of 40 items answered correctly, or $69.2 \%$. Two students scored a perfect 40 of 40 .

We used ordinary least squares (OLS) regression, and SAS Version 9.1, to estimate parameter coefficients for each of the six models. Although the dependent variable was limited to values between 0 and 40 for the model of the overall score, and to values between 0 and 100 for the models of the five sub-scores, limited dependent variable techniques yielded quite similar results to those reported for OLS. We employed a significance level of 0.05 on all hypothesis tests. When testing the coefficient of total credit hours completed, we hypothesized a positive relationship between that factor and the number of WGCTA items (or the percentage of items on each test) answered correctly.

\section{RESULTS}

All OLS coefficient estimates appear in Table 2. The coefficient of total credit hours completed was positive and significant at the 0.05 level. This result supports our hypothesis that a business curriculum does develop critical thinking ability, or at least serves as filter for critical thinking ability. However, examination of the coefficient for credit hours completed in each of the five sub-score models reveals some potential insights into the specific areas of critical thinking that appear to be developed or filtered in coursework. (We reiterate Watson and Glaser's cautions regarding the reliability of the sub-scores as specific measures, however.) Whereas credit hours completed are not significantly related to the ability to make accurate inferences (test 1), recognize assumptions (test 2), or make proper deductions (test 3) - although coefficients do take the expected positive sign in each case coursework completed is significantly related to interpreting information (test 4) and evaluating arguments (test 5). This is particularly true of interpreting information, which had by far and away the largest coefficient value and the highest significance level. This result is made more interesting by noting from Table 1 that average student scores were the second lowest in this area (at $65.4 \%$ ), among all five sub-scores.

In terms of our control variables, neither declared major, course instructor, nor the term in which the appraisal was administered were significantly related to WGCTA performance overall or in any of the sub-scores, save one instance: Financial Services majors differed on making accurate inferences.

However, in contrast to the reports of Watson and Glaser (2006), our results exhibit a bias in favor of males. However, review of the coefficients for males in each sub-score model indicates that this bias appears significant only for interpreting information, where the coefficient value indicates a relatively large 11.35 percentage point advantage for males versus females. 
Table 1: Summary Statistics for All Variables (n=584)

\begin{tabular}{|c|c|c|c|c|}
\hline Variable & Mean & Standard Deviation & Minimum & Maximum \\
\hline WGCTA items correct & 27.6695 & 5.5021 & 13 & 40 \\
\hline Percent correct on Test 1 & 58.1703 & 24.7010 & 0 & 100 \\
\hline Percent correct on Test 2 & 70.7406 & 27.7883 & 0 & 100 \\
\hline Percent correct on Test 4 & 65.3620 & 21.7282 & 0 & 100 \\
\hline Percent correct on Test 5 & 74.4863 & 17.6539 & 0 & 100 \\
\hline Total credit hours & 91.4005 & 20.2708 & 60 & 254 \\
\hline Male & 0.5274 & 0.4997 & 0 & 1 \\
\hline Black & 0.1233 & 0.3290 & 0 & 1 \\
\hline Hispanic & 0.0908 & 0.2875 & 0 & 1 \\
\hline Asian & 0.0702 & 0.2557 & 0 & 1 \\
\hline White & 0.7089 & 0.4547 & 0 & 1 \\
\hline Management major & 0.3630 & 0.4813 & 0 & 1 \\
\hline Marketing major & 0.1079 & 0.3105 & 0 & 1 \\
\hline Accounting major & 0.1695 & 0.3755 & 0 & 1 \\
\hline Finance major & 0.2021 & 0.4019 & 0 & 1 \\
\hline Trans/Logistics major & 0.0462 & 0.2102 & 0 & 1 \\
\hline Financial services major & 0.0205 & 0.1420 & 0 & 1 \\
\hline Economics major & 0.0120 & 0.1089 & 0 & 1 \\
\hline Instructor 1 & 0.1130 & 0.3169 & 0 & 1 \\
\hline Instructor 2 & 0.4538 & 0.4983 & 0 & 1 \\
\hline Instructor 3 & 0.0531 & 0.2244 & 0 & 1 \\
\hline Instructor 4 & 0.3801 & 0.4858 & 0 & 1 \\
\hline Spring & 0.5428 & 0.4986 & 0 & 1 \\
\hline Summer & 0.1010 & 0.3016 & 0 & 1 \\
\hline Fall & 0.3562 & 0.4793 & 0 & 1 \\
\hline Proportion hours transferred & 0.5235 & 0.3325 & 0 & 1 \\
\hline
\end{tabular}

Table 2: Ordinary Least Squares Coefficients (n=584)

Reported significance levels are two-tailed, except those for total credit hours completed, which are one-tailed in the hypothesized (positive) direction. Test $1=$ accurate inferences, test $2=$ recognizing assumptions, test $3=$ making proper deductions, test $4=$ interpreting information, and test $5=$ evaluating arguments.

\begin{tabular}{|c|c|c|c|c|c|c|c|c|c|c|c|c|}
\hline Variable & Overall & & Test 1 & & Test 2 & & Test 3 & & Test 4 & & Test 5 & \\
\hline Intercept & 26.0642 & $* * *$ & 59.2410 & **** & 66.2660 & $* * *$ & 76.8090 & $* * *$ & 50.1330 & $* * *$ & 68.8200 & **** \\
\hline Total credit hours completed & 0.0259 & $*$ & 0.0356 & & 0.0667 & & 0.0282 & & 0.1340 & $* *$ & 0.0690 & $*$ \\
\hline Male & 1.1274 & $*$ & -0.1310 & & 2.3480 & & 1.6830 & & 11.3450 & $* * *$ & 0.0359 & \\
\hline Hispanic & -2.2233 & $* *$ & -4.3490 & & -7.5710 & & -6.4160 & $*$ & -5.4660 & & -3.9240 & \\
\hline Asian & -2.6620 & $* *$ & -8.4910 & $*$ & -4.9050 & & -10.5330 & $* *$ & -6.9440 & * & -2.6800 & \\
\hline Marketing major & -0.5697 & & -2.7540 & & -3.6400 & & -0.6920 & & -0.1640 & & -0.1340 & \\
\hline Accounting major & 0.3453 & & 0.0885 & & 2.8710 & & -0.4450 & & 2.4610 & & -0.2540 & \\
\hline Finance major & 0.3739 & & 0.4940 & & -1.6650 & & 2.8790 & & 3.0160 & & 0.0265 & \\
\hline International business major & -0.0014 & & 1.5250 & & -2.5830 & & -1.8660 & & 2.5880 & & 0.9470 & \\
\hline Trans/Logistics major & 1.2550 & & 1.6590 & & 2.6440 & & 1.0350 & & 5.1260 & & 5.2810 & \\
\hline Financial services major & 2.0841 & & 15.8240 & $*$ & 10.4860 & & 1.6300 & & 7.3280 & & -5.8020 & \\
\hline Economics major & -0.0237 & & -2.7790 & & 4.2780 & & 8.3680 & & -5.4100 & & -6.0640 & \\
\hline Instructor 1 & 0.9684 & & -0.6080 & & 0.3190 & & 2.1050 & & 5.4640 & & 4.5950 & \\
\hline Instructor 2 & 0.4276 & & 3.0090 & & 0.9940 & & -0.4080 & & 2.5170 & & -0.0227 & \\
\hline Instructor 3 & 0.1695 & & 0.0420 & & 2.9320 & & 1.8540 & & -0.6110 & & -2.1350 & \\
\hline Fall & -0.5477 & & -3.7850 & & -1.2130 & & -2.4170 & & -1.1870 & & 1.2770 & \\
\hline Proportion of transfer hours & -1.4337 & $*$ & -3.7610 & & -0.9320 & & -6.1920 & $*$ & -5.9950 & $*$ & -1.3230 & \\
\hline
\end{tabular}

*** Significant at 0.001 level

** Significant at 0.01 level

* Significant at 0.05 level

Again in contrast to Watson and Glaser (2006), we also find a minority bias, as the coefficients of all three minority categories were significant and negative in the model of overall scores. This bias was significant across four of the five sub-scores for black students and across three of the four sub-scores for Asian students. The scores for Hispanic students differed significantly only on making proper deductions. The only area in which no significant differences were found between white and minority students was in evaluating arguments. 
Finally, we find that students with higher proportions of transfer hours do indeed perform significantly worse overall than those who transfer in fewer hours. Stated more generally, non-transfers (or those who transfer fewer hours) tend to do better than transfers. More specifically, this difference is significant when it comes to making proper deductions and interpreting information (in addition, the coefficients for this factor in the other subscore models are consistently negative, although not significantly so). As a large number of the transfer hours come from the community college system, this result may very well be a proxy for general academic preparation and/or specific ability in the first place. However, it also raises questions as to how well these schools develop or filter critical thinking ability, particularly in those two areas.

\section{CONCLUSIONS}

Our findings show a significant relationship between credit hours completed and critical thinking ability. However, our analysis involved a convenience sample and did not involve a true pre-test/post-test equivalent group experimental design in which the same subjects were analyzed early and then again late in their program of study. ${ }^{1}$ Because of this, determining whether the curriculum developed this ability versus whether it simply filtered out those students with lesser abilities is a matter of some conjecture. ${ }^{2}$ However, recent reports from the dean of the college in which this study was conducted indicate that the retention of business majors is quite high once they reach their junior level coursework (i.e., the level at which we administered the instrument). If retention is indeed high from that point, it would imply that our sub-sample of students with high (or higher credit hours) had not been significantly filtered. That would also tend to imply that the curriculum is developing critical thinking ability and not simply serving as a hurdle.

\section{AUTHOR INFORMATION}

B. Jay Coleman, Ph.D. is the Richard deRaismes Kip professor of Operations Management and Quantitative Methods at the University of North Florida (UNF). He has written extensively on issues related to sports, education, and quantitative management. E-mail: jcoleman@unf.edu

Paul M. Mason, Ph.D. is the Richard deRaismes Kip professor of Economics and Chairman of the Department of Economics and Geography at UNF. Dr. Mason has written numerous articles on economics education, the economics of gaming, and sports economics. E-mail: pmason@unf.edu. Corresponding author.

Jeffrey W. Steagall, Ph.D. is the Dean of the Goddard School of Business \& Economics at Weber State University. Dr. Steagall is the author of numerous treatise on international economics, economics education, study abroad education. E-mail: jeffsteagall@weber.edu

\section{REFERENCES}

1. Behar-Horenstein, LS. and Lian Niu. 2011. Teaching Critical Thinking Skills In Higher Education: A Review Of The Literature. Journal of College Teaching and Learning. Vol. 8, No. 2.

2. Borg, $M$ and Stranahan H. 2006. Do introductory economics courses enhance critical thinking? Paper presented at the Western Economic Association meetings

3. Burbach, M., Matkin, G., and Fritz, S. 2004. Teaching critical thinking in an introductory leadership course utilizing active learning strategies. College Student Journal 38 (3), 482-493.

4. Carrithers D and Bean JC. 2008. Using a client memo to assess critical thinking of finance majors. Business Communication Quarterly 71(1): 10-26.

5. Fisher, A. 2001. Critical thinking: an introduction. Cambridge University Press.

\footnotetext{
${ }^{1}$ However, assuming sufficient randomization of subjects across the sample, and a reasonable sample size, this shortcoming is mitigated.

${ }^{2}$ Note that from an assurance of learning / accreditation perspective, either option is acceptable. As long as unprepared (or under-prepared) students are not being granted degrees, it does not necessarily matter how this objective is achieved, whether it be by developing the student's knowledge / skills, or by filtering out those without such knowledge / skills.
} 
6. Giancarlo, CA and Facione, PA. 2001. A look across four years at the disposition toward critical thinking among undergraduate students. The Journal of General Education 50 (1): 29-55.

7. Halpern, D. F. (1999). Teaching for critical thinking: Helping college students develop the skills and dispositions of a critical thinker. New Directions for Teaching and Learning, 80, 69-74.

8. Harcourt assessment. 2008. Watson-Glaser Critical Thinking Appraisal@. harcourtassessment.com/haiweb/cultures/en-us/productdetail.htm?pid=015-8191-013 [20 May 2008]

9. King, P., Wood, P., \& Mines, R. (1990). Critical thinking among college and graduate students. Review of Higher Education, 13(2), 167-186.

10. MacPherson, K. 1999. The development of critical thinking skills in undergraduate supervisory management unity: efficacy of student peer assessment. Assessment and Evaluation in Higher Education 24 (3): 273-284.

11. Miller, M. 1992. Outcomes evaluation: measuring critical thinking. Journal of Advanced Nursing 17: 14011407.

12. Niedringhaus, L. 2001. Using student writing assignments to assess critical thinking skills: a holistic approach. Holistic Nursing Practice 15 (3): 9-17.

13. Pantesting.com. 2008. Watson-Glaser Critical Thinking Appraisal. www.pantesting.com/products/Psychcorp/wgcta.asp [20 May 2008]

14. Rudinow J and Barry VE. 1994. Invitation to critical thinking. Harcourt Brace.

15. Stratton, J. 1999. Critical thinking for college students. Rowman \& Littlefield Publishers, Inc.

16. Watson, G and Glaser EM. 1952. Watson-Glaser Critical Thinking Appraisal. Harcourt, Brace \& World, Inc.

17. Watson, G and Glaser EM. 2006. Watson-Glaser Critical Thinking Appraisal Short Form Manual. Harcourt Assessment, Inc.

18. Williams, Steve W. 2002. Making better business decisions: understanding and improving critical thinking and problem-solving skills. Sage Publications.

19. Zascavage V, Masten W, Schroeder-Steward J, Nichols C. 2007. Comparison of critical thinking in undergraduates and graduates in special education. International Journal of Special Education 22(1): 25-

31. Available online at www.internationalsped.com/documents/3\%20Zascavage.doc. 
NOTES 